ТЕЛЕМАТИКА И ДИАГНОСТИКА ТРАНСПОРТНЫХ СРЕДСТВ

\author{
В.Н. Щукина, С. Н.Девянин, А.М.Зейлигер \\ Российский государственный аграрный университет - \\ Московская сельскохозяйственная академия им. К.А. Тимирязева, г. Москва \\ firstnotbarbara@gmail,.com devta@rambler.ru, azeiliguer@mail.ru
}

\begin{abstract}
Аннотация. Для повышения продуктивности и сокращения издержек в сельском хозяйстве применяется концепция умного сельского хозяйства. Одной из технологий умного сельского хозяйства является телематика. Концепция телематики позволяет проводить удаленный сбор данных с подключенных устройств, обрабатывать информацию и отображать ее в различных интерфейсах. Выявлено несколько целей внедрения систем транспортной телематики: 1. Постоянный мониторинг технического состояния техники; 2. Снижение затрат (в том числе на ГСМ, запчасти и шины); 3. Контроль качества вождения и продуктивности работников; 4. Повышение продуктивности работы, за счет автоматизации документооборота транспортного отдела; 5. Снижение ответственности собственника автопарка за ДТП. Схема реализации мониторинга транспортного средства заключается в следующем: на транспортное средство устанавливается приемно-передающее устройство, с помощью которого поддерживается связь с внешним миром (спутниками, станциями технического обслуживания и др.); с него данные передаются на сервер, где они анализируются и сохраняются; в случае экстренной ситуации (поломки, аварии угона и др.) данные передаются в полицию, скорую помощь, станцию технического обслуживания для немедленного реагирования на проблему; в свою очередь владелец всегда может контролировать состояние транспортного средства и управлять частью функций удаленно. Для реализации данной концепции, нужно реализовать бесперебойную связь с транспортным средством, а также доработать системы диагностики технического состояния, чтобы минимизировать возможность появления экстренных ситуаций. Необходима разработка системы, позволяющий работать на упреждение неисправностей. При внедрении упреждающей системы диагностики будет возможно в режиме реального времени следить за показателями с датчиков и своевременно предсказывать необходимость ремонта. Так же, при внедрении диагностики по косвенным признакам, можно расширить количество диагностируемых элементов, в том числе возможно будет узнать состояние механических компонентов.

Ключевые слова: телематика, диагностика транспортного средства, удаленная диагностика
\end{abstract}

\section{Введение}

Современное сельскохозяйственное производство работает по тем же принципам, что и любая другая сфера бизнеса - постоянное стремление снизить себестоимость единицы продукции повысить производительность в расчете на единицу затраченных ресурсов. На протяжении прошлого века достигать данных целей позволяло использование все более экономичных сельхозмашин, высокоурожайных сортов растений, рациональных агротехнологических приемов.

Сегодня эти инструменты по-прежнему актуальны, но их потенциал практически достиг предела, возможного при современном уровне технологий. В то же время появились новые технологии и инструменты, недоступные прежде. Например, спутниковые и компьютерные технологии, ставшие общедоступными.

Технологии, развивающиеся с нарастающими темпами, постепенно входят и в сельское хозяйство. Для повышения продуктивности и сокращения издержек применяется концепция умного сельского хозяйства. Умное сельское хозяйство - принцип ведения сельскохозяйственной деятельности при помощи внедрения новых технологий: «интернет вещей», беспилотных летательных аппаратов, GPS и ГЛОНАСС, автоматизирующих систем и т.п., с целью повышения урожайности и уменьшении затрат на издержки, телематика и др.

На рисунке 1 [1] представлена схема работы системы умного сельского хозяйства. Предполагается установка датчиков для сбора информации о состоянии того или иного объекта сельского хозяйства - животные, растения, техника и др. Информация с датчиков стекается в приемник и передается на сервер для дальнейшей обработки и анализа. Проанализированную информацию получает человек для принятия своевременных мер, если какие-то показатели выходят за допустимый предел.

Рассмотрим более подробно, одну из технологий технологию мониторинга автотранспорта и сельхозтехники. Чтобы сохранить и поддерживать на должном уровне состояние техники, необходимо внедрение технологий мониторинга техники в процессе ее эксплуатации. Данной проблемой занимается отдельная область информатики - телематика.

Телематика (понятие, объединяющее в себе «телекоммуникация» и «информатика») - это удаленный 
сбор данных с подключенных устройств, обработка информации и последующее ее отображение в различных интерфейсах. В различных вариантах применения телематики данные могут передаваться из транспортного средства, обрабатываться телематическими службами и возможно также передаваться далее, а также данные могут передаваться в транспортное средство и там обрабатываться. $[2,3]$.

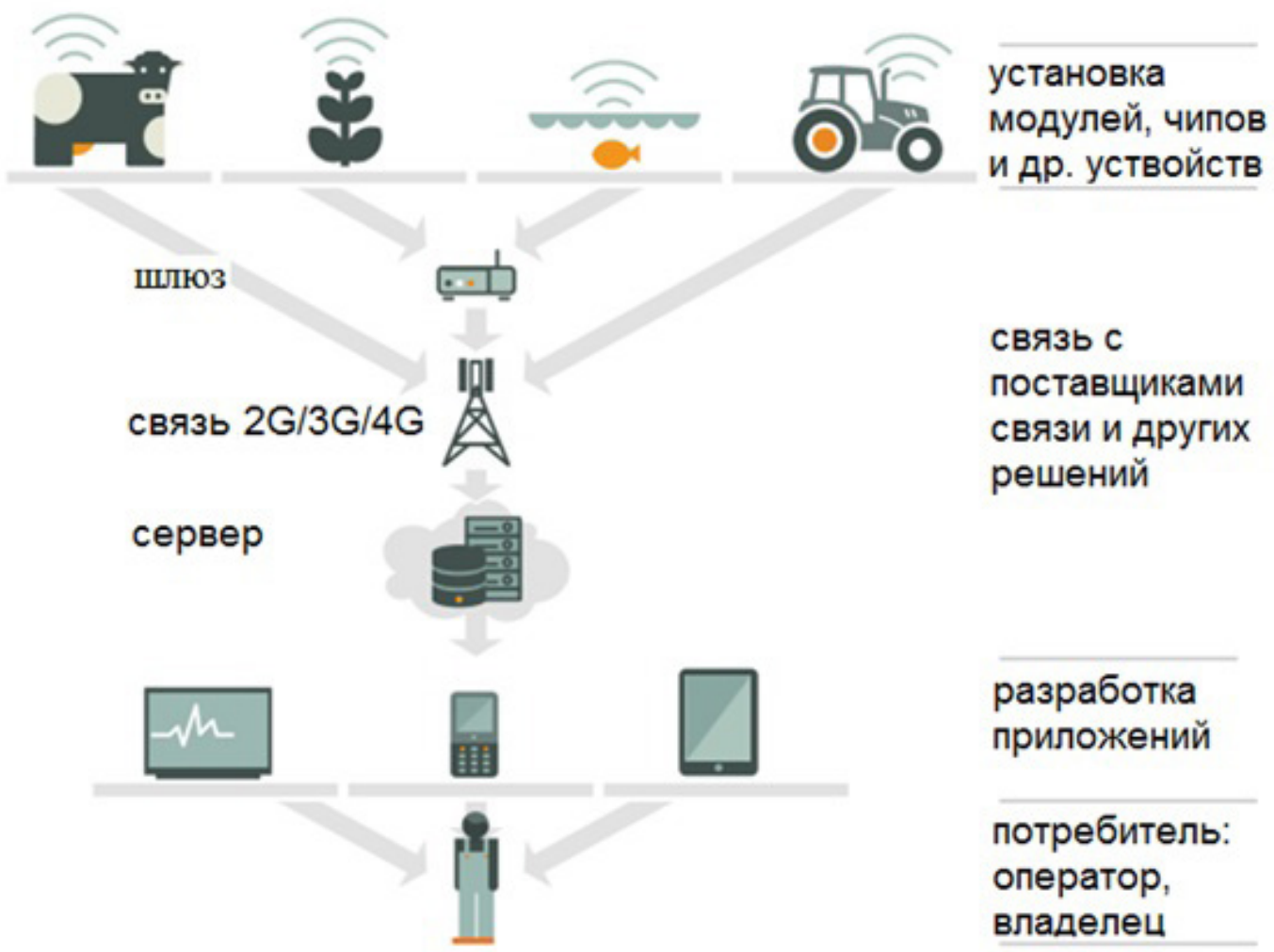

Рис. 1 - Принцип работы системы умного сельского хозяйства

\section{Теледиагностика}

Одной из уже используемой функцией телематики является функция теледиагностики. Наряду с точным местоположением и данными автомобиля (номер шасси, модель, год выпуска, пробег) в сервисную службу или службу клиентской поддержки передается информация о температуре двигателя, напряжении аккумуляторной батареи и сохраненные сообщения о неисправностях и предупреждениях. Это обеспечивает в случае аварии целенаправленную техническую помощь.

Есть несколько функций телематики, которые реализовываются в некоторых компаниях. Например, так называемая функция TeleService. При этом посредством SMS через мобильного оператора дилеру передается информация о необходимости технического обслуживания за четыре недели до установленного срока. Таким образом, дилер информируется о необходимости проведения обслуживания, после этого он связывается с клиентом по телефону для согласования срока проведения обслуживания. Работа такой функции предполагает оснащение автомо- биля системой телефона/телематики и на сегодняшний день доступна только в некоторых странах.

Сейчас активно внедряются системы мониторинга техники во всех областях. По данным исследования профильного американского издания Field Technologies (проведенного среди подписчиков) $43 \%$ опрошенных пользуются системами мониторинга транспорта, и еще 24 \% планируют внедрять подобные решения в ближайшее время (в США) [4].

Выявлено несколько целей внедрения систем транспортной телематики:

- Постоянный мониторинг технического состояния техники;

- Снижение затрат (в том числе на ГСМ, запчасти и шины);

- Контроль качества вождения и продуктивности работников;

- Повышение продуктивности работы, за счет автоматизации документооборота транспортного отдела;

- Снижение ответственности собственника автопарка за ДТП. 


\section{Диагностика транспортного средства}

На рисунке 2 [2] представлена схема реализации мониторинга транспортного средства. На транспортное средство установлено приемно-передающее устройство, с помощью которого поддерживается связь с внешним миром (спутниками, станциями технического обслуживания и др.). С него данные передаются на сервер, где они анализируются и сохраняются. В случае экстренной ситуации (поломки, аварии угона и др.) данные передаются в полицию, скорую помощь, станцию технического обслуживания для немедленного реагирования на проблему. В свою очередь владелец всегда может контролировать состояние транспортного средства и управлять частью функций удаленно. Это схема далекого будущего. Сейчас необходимо реализовать бесперебойную связь с транспортным средством, а также доработать системы диагностики технического состояния, чтобы минимизировать возможность появления экстренных ситуаций.

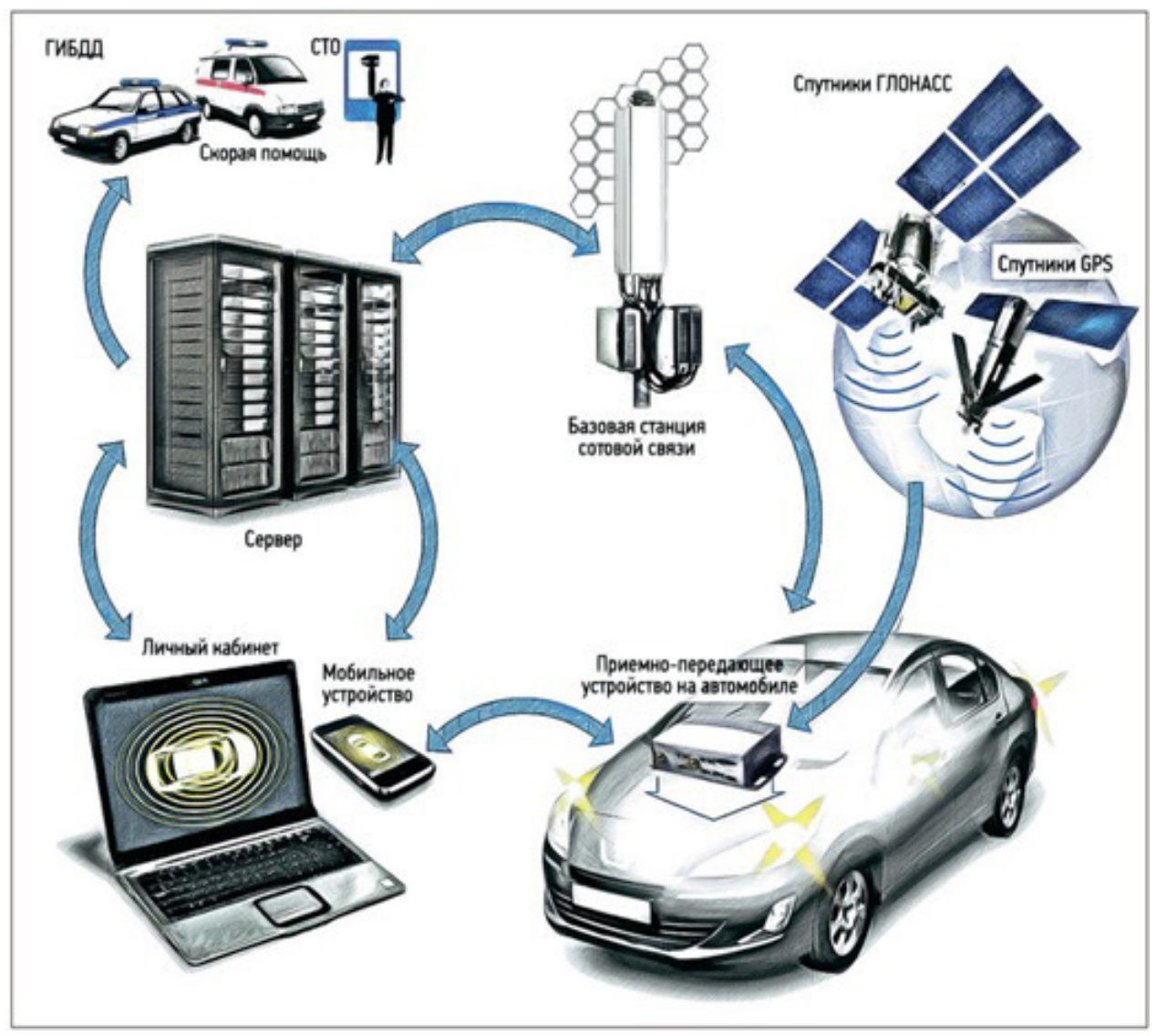

Рис. 2 - Схема мониторинга транспортного средства

На данный момент транспортные средства оснащены различными датчиками контроля технического состояния, но информация может быть считана только на станции технического обслуживания [5-7]. То есть, сейчас предотвратить появление неисправности нельзя. Необходима разработка системы, позволяющий работать на упреждение неисправностей.

При внедрении упреждающей системы диагностики будет возможно в режиме реального времени следить за показателями с датчиков и своевременно предсказывать необходимость ремонта. Так же, при внедрении диагностики по косвенным признакам, можно расширить количество диагностируемых элементов, в том числе возможно будет узнать состояние механических компонентов (например в двигателе - цилиндров, коленчатого вала и других).
Оповещение о необходимости ремонта будет происходить по следующей схеме: от машины информация передается к модели субъекта управления, сохраняется и обрабатывается и при необходимости ремонта модель субъекта управления (например, оператор) принимает решение о необходимости ремонта и информирует сервисную службу о прибытии техники на ремонт. При росте технологий, модель субъекта управления может стать интеллектуальной системой, которая без участия человека будет принимать решение.

\section{Недостатки разрабатываемых систем:}

1. Дороговизна. На внедрение этих технологий нужны немалые средства, которых у большинства предприятий не хватает. Даже с учетом хорошей 
окупаемости не каждое хозяйство может позволить себе технологии точного земледелия.

2. Техническая сложность. По сути речь идет о современных сложных компьютерных технологиях. Не просто найти специалистов, способных не то что внедрить, а хотя бы обслуживать системы точного земледелия.

3. Отсутствие практического опыта. Быстрый технический прогресс означает, что нет достаточной практики применения технологий, следовательно, невозможно адекватно оценить эффективность их применения в тех или иных условиях.

\section{Заключение}

Недостатки нельзя считать существенной причиной для отказа от использования телематики в принципе. Очевидно, что за этим будущее, и те предприятия, которые раньше освоят данные технологии, получат следующие существенные преимущества в конкурентной борьбе:

1. Оптимизация (минимизация) затрат сырья и расходных материалов (топлива, запасных частей).
За счет своевременного выявления неисправностей и ремонтных воздействий, можно снизить затраты на топливо и уменьшить будущий износ техники, что позволит снизить затраты на ремонт.

2. Снижение риска срыва агротехнических сроков (для сельского хозяйства). Благодаря заблаговременному предсказанию появления неисправности, можно предотвращать поломки «в поле».

3. Корректировка расписания в режиме онлайн. Благодаря упреждающей диагностики, можно предсказывать выход из строя того или иного транспортного средства и в режиме реального времени корректировать расписание движения.

4. Своевременное устранение неисправностей. Данное мероприятие позволит снизить последующие затраты на топливо и ремонт, за счет поддержания исправного технического состояния.

5. Снижение негативного влияния на окружающую среду. Благодаря своевременному устранению неисправностей, можно уменьшить расход топлива и продлить срок службы транспортного средства, что поможет снизить выбросы в окружающую атмосферу.

\section{Список литературы}

1. Умное сельское хозяйство. [Электронный ресурс]. URL: https://iot.ru/selskoe-khozyaystvo/selskoe-khozyaystvo-po-umnomu (дата обращения: 15.06.2018).

2. Все о телематике. [Электронный ресурс]. URL: http://www.zr.ru/content/articles/737283-chto-takoe-telematika-udalennyj-dostup/ (дата обращения: 15.06.2018).

3. Телематика. [Электронный ресурc]. URL: https://naked-science.ru/article/column/telematika-ot-avto-do-velosipedov (дата обращения: 15.06.2018).

4. Рынок мониторинга транспорта. [Электронный ресурс]. URL: vestnik-glonass.ru/ ygp4w (дата обращения: 15.06.2018).

5. С.Н. Девянин, В.Н. Щукина, Системы управления двигателем / С.Н. Девянин, В.Н. Щукина / Международный технико-экономический журнал - 2015. - № 6. - С. 11-14.

6. Е.Ф. Шульга, В.Н. Щукина. Мониторинг качества движения и технического состояния транспортных средств / С.Н. Девянин, В.Н. Щукина / Вестник Федерального государственного образовательного учреждения высшего профессионального образования «Московский государственный агроинженерный университет имени В.П. Горячкина» - 2017. - №4(80). - С. 18-22.

7. Соснин Д.А., Яковлев В.Ф. Новейшие автомобильные электронные системы/ Соснин Д.А., Яковлев В.Ф. - М.: СОЛОНПресc, 2005. - 240 c. 


\title{
TELEMATICS AND DIAGNOSTICS OF THE VEHICLES
}

\author{
Shchukina V.N., Devyanin S.N, ZeyligerA.M. \\ Russian State Agrarian University - Moscow Timiryazev Agricultural Academy
}

Abstract. The concept of smart agriculture is applied in agriculture, for increasing of productivity and reducing of costs. One of the technologies of smart agriculture is telematics. The concept of telematics allows remote collection of data from connected devices, processing information and displaying it in various interfaces. Several objectives of the introduction of transport telematics systems have been identified: 1. Constant monitoring of the technical state of machinery; 2 . Reducing of costs (including fuel, spare parts and tires); 3 . Quality control of driving and employee productivity; 4. Increasing of productivity of the work, by automating the workflow of the transport department; 5 . Reducing the liability of the owner for an accident. The scheme for implementing vehicle monitoring is as follows: a receiving and transmitting device is installed on the vehicle, through which communication with the outside world (satellites, maintenance stations, etc.) is maintained; from it the data is transferred to the server, where they are analyzed and stored; in case of an emergency situation (breakdown, etc.), the data are transferred to the police, ambulance, maintenance station for immediate response to the problem; in turn, the owner can always monitor the state of the vehicle and manage part of the functions remotely. To implement this concept, it is necessary to realize an uninterrupted connection with the vehicle, as well as to refine the diagnostic systems of the technical state in order to minimize the possibility of occurrence of emergency situations. It is necessary to develop a system that allows you to work on preventing malfunctions. When implementing a proactive diagnostic system, it will be possible in real time to monitor the indicators from the sensors and promptly predict the need for repair. Also, when introducing diagnostics by indirect indications, it is possible to expand the number of diagnosed elements, including possible to know the state of mechanical components.

Key words: telematics, vehicle diagnostics, remote diagnostics

\section{References}

1. Umnoe sel'skoe hozjajstvo. [Electronic resource]. URL: https://iot.ru/selskoe-khozyaystvo/selskoe-khozyaystvo-po-umnomu (data obrashhenija: 15.06.2018) (In Russian).

2. Vse o telematike. [Electronic resource]. URL: http://www.zr.ru/content/articles/737283-chto-takoe-telematika-udalennyj-dostup/ (data obrashhenija: 15.06.2018) (In Russian).

3. Telematika. [Electronic resource]. URL: https://naked-science.ru/article/column/telematika-ot-avto-do-velosipedov (data obrashhenija: 15.06.2018) (In Russian).

4. Rynok monitoringa transporta. [Electronic resource]. URL: vestnik-glonass.ru/ ygp4w (data obrashhenija: 15.06.2018) (In Russian).

1. S.N. Devjanin, V.N. Shhukina. Sistemy upravlenija dvigatelem / S.N. Devjanin, V.N. Shhukina / Mezhdunarodnyj tehniko-jekonomicheskij zhurnal - 2015. - № 6. - S. 11-14 (In Russian).

2. E.F. Shul'ga, V.N. Shhukina. Monitoring kachestva dvizhenija i tehnicheskogo sostojanija transportnyh sredstv / S.N. Devjanin, V.N. Shhukina / Vestnik Federal'nogo gosudarstvennogo obrazovatel'nogo uchrezhdenija vysshego professional'nogo obrazovanija «Moskovskij gosudarstvennyj agroinzhenernyj universitet imeni V.P. Gorjachkina» - 2017. - №4(80). - S. 18-22 (In Russian). 